\title{
A method for comparing properties of cirrus clouds in global climate models with those retrieved from IR sounder satellite observations
}

\author{
Johannes Hendricks ${ }^{1 *}$, Andreas Falb ${ }^{1,2}$, Claudia J. StubenrauCH ${ }^{3}$ and Claudia Emde ${ }^{1,4}$
}

${ }^{1}$ Deutsches Zentrum für Luft- und Raumfahrt (DLR), Institut für Physik der Atmosphäre, Oberpfaffenhofen, Germany

${ }^{2}$ now at: Bayerisches Landesamt für Umwelt, Augsburg, Germany

${ }^{3}$ Laboratoire de Météorologie Dynamique, CNRS/IPSL UMR 8539, Ecole Polytechnique, Palaiseau, France

${ }^{4}$ now at: Meteorologisches Institut, Ludwig-Maximilians-Universität, Munich, Germany

(Manuscript received October 28, 2009; in revised form July 20, 2010; accepted July 30, 2010)

\begin{abstract}
A methodology to compare cloud properties simulated by global climate models with those retrieved from observations by satellite-based infrared (IR) sounders has been developed. The relatively high spectral resolution in the $\mathrm{CO}_{2}$ absorption band of these instruments leads to especially reliable cirrus properties, day and night. Additionally, bulk microphysical properties can be retrieved for semi-transparent cirrus, based on the observed spectral emissivity differences between 8 and $11 \mu \mathrm{m}$. The particular intention of this study is to compare macro- and microphysical properties of high cloudiness as represented by the model simulations and the satellite data. For this purpose, a method has been developed to process the model output to be comparable to the satellite measurements, as in other observational simulator packages (for example the ISCCP-simulator). This simulator method takes into account i) the differences in horizontal resolution of the model and the observations, ii) the specific observation time windows, iii) the determination of the pressure of a cloud system, identified with the pressure at the middle of the uppermost cloud, and iv) the selection of high clouds with specific cloud optical thickness ranges for the microphysical property retrieval using IR sounder data. Applying this method to simulations by the global climate model ECHAM and TOVS satellite observations has important effects. The frequency of high clouds selected from the model output by using the method is significantly smaller than the total frequency of high cloudiness in the model. Largest differences occur around the equator where the zonal mean frequency of high cloudiness is reduced by about $30 \%$ (relative change). The selection method is essential for the comparison of modelled and observed microphysical properties of high clouds. The selection of high clouds from the ECHAM simulation according to the optical thickness range of the TOVS data results in a reduction of the mean water path of high clouds by factors of more than 3 compared to the case where also high clouds of other optical thicknesses are considered. Furthermore, the selection by optical thickness causes a significant increase in the mean effective cloud particle diameter. These changes significantly reduce the differences between the simulation and the observations. The method can also be applied for comparisons with other IR sounder climatologies such as from AIRS and IASI.
\end{abstract}

\section{Zusammenfassung}

Es wurde eine Methodik entwickelt mit deren Hilfe man Wolkeneigenschaften, die mit einem globalen Klimamodell simuliert wurden, mit Beobachtungsdaten vergleichen kann, welche aus Messungen mit satellitengestützten Infrarotsensoren abgeleitet wurden. Die relativ hohe spektrale Auflösung derartiger Instrumente im $\mathrm{CO}_{2}$ Absorptionsband erlaubt eine zuverlässige Bestimmung von Zirruseigenschaften, sowohl für Tag- als auch Nachtbedingungen. Zusätzlich können, auf Basis von Differenzen der spektralen Emissivität bei 8 und $11 \mu \mathrm{m}$, mikrophysikalische Wolkeneigenschaften semi-transparenter Zirruswolken abgeleitet werden. Die spezielle Intention dieser Studie ist der Vergleich von modellierten makro- und mikrophysikalischen Eigenschaften hoher Bewölkung mit derartigen Beobachtungsdaten. Dazu wurde eine Methode entwickelt, die die Modellergebnisse hinsichtlich der Vergleichbarkeit mit den Satellitendaten prozessiert, ähnlich wie in anderen Satellitensimulatoren (zum Beispiel dem ISCCP-Simulator). Die Simulatormethode berücksichtigt: i) die unterschiedliche horizontale Auflösung von Modell- und Satellitendaten, ii) die spezifischen Beobachtungszeitfenster, iii) die Bestimmung des Druckes eines Wolkensystems, identifiziert mit dem Druck in der Mitte der obersten Wolke, und iv) die Selektion hoher Wolken spezifischer optischer Dicke zur Ableitung mikrophysikalischer Wolkeneigenschaften aus den Infrarotsensordaten. Die Anwendung der Methode auf Simulationsergebnisse des Klimamodells ECHAM und TOVS Satellitendaten hat wichtige Effekte. Die Häufigkeit der hohen Wolken, welche mit der Methode aus den Modellergebnissen selektiert wurden, ist deutlich geringer als die gesamte Häufigkeit hoher Wolken im Modell. Die größten Unterschiede treten im Bereich des Äquators auf, wo die zonal gemittelte Häufigkeit der hohen Bewölkung um etwa $30 \%$ (relative Änderung) verringert wird.

*Corresponding author: Johannes Hendricks, Deutsches Zentrum für Luft- und Raumfahrt (DLR), Institut für Physik der Atmosphäre, Oberpfaffenhofen, 82234 Wessling, Germany, e-mail:

Johannes.Hendricks@dlr.de 
(Fortsetzung Zusammenfassung) Für den Vergleich von modellierten und beobachteten mikrophysikalischen Eigen schaften hoher Wolken ist die Selektionsmethode von wesentlicher Bedeutung. Die Selektion hoher Wolken aus den ECHAM-Simulationen, entsprechend der für TOVS relevanten optischen Dicken, resultiert in einer Verringerung des mittleren Wasserpfades hoher Wolken um Faktoren von mehr als 3, verglichen mit dem Fall, bei dem auch hohe Wolken anderer optischer Dicke berücksichtigt werden. Zusätzlich bewirkt die Selektion nach optischer Dicke eine signifikante Erhöhung des Effektivdurchmessers der Wolkenpartikel. Diese Änderungen haben eine deutliche Verringerung der Abweichungen zwischen Modell und Beobachtung zur Folge. Die Methode kann auch zu Vergleichen mit Wolkenklimatologien verwendet werden, welche aus Messungen anderer Infrarotsensoren abgeleitet wurden, beispielsweise aus AIRS- und IASI-Daten.

\section{Introduction}

Clouds are important regulators of the Earth's radiation budget and, therefore, play one of the key roles in the climate system. Cirrus clouds are the most frequent cloud type in the upper troposphere. They cover $20-40 \%$ of the globe (e.g., LIOU, 1986; Rossow and SCHIFFER, 1999; Wylie and MenZel, 1999; StubenRauch et al., 2006, 2010) and have important effects on climate (e.g., CHEN et al., 2000). Hence, cirrus clouds should be properly represented in general circulations models (GCM) which are used to study the global climate system.

Many studies reveal that anthropogenic changes in the concentration and properties of cloud forming aerosols can lead to significant perturbations of cloud microphysical and optical properties as well as cloud lifetime (e.g., LOHMANN and FeICHTER, 2005). These cloud perturbations have the potential to affect climate significantly. To investigate the global effects of aerosol-cirrus interactions, LOHMANN (2002), LOHMANN and KÄRCHER (2002), and LOHMANN et al. (2003, 2004) included ice microphysics and parameterizations of aerosol-induced cirrus cloud formation in the ECHAM GCM. Microphysical ice cloud properties, particularly the ice water content, the crystal concentration and effective size (MCFARQUHAR and HEYMSFIELD, 1998), simulated with the resulting model were evaluated by comparisons with observational data gained from aircraft, radiosondes and ground-based remote sensing. Satellite observations were mainly used to evaluate macrophysical cloud properties like total or high cloud cover as well as cloud radiative forcing. Hence, the evaluation of ice cloud microphysical parameters was restricted to specific locations and, in many cases, specific episodes. Therefore, a supplemental evaluation of the modelled ice cloud microphysical properties from a global and long-term point of view is desirable.
The relatively high spectral resolution in the $\mathrm{CO}_{2} \mathrm{ab}-$ -sorption band of IR sounders allows a good identification of cirrus clouds, day and night. These instruments measure radiation emitted and scattered from different levels of the atmosphere, and are on board different satellites, since the early 1980's: The TIROS-N Operational Vertical Sounders (TOVS; SMITH et al., 1979) on board the NOAA polar satellites, then since 2002 the Atmospheric InfraRed Sounder (AIRS; AUMANN et al., 2003) on board the Earth Observing System (EOS) platform Aqua, and the IR Atmospheric Sounding Interferometer (IASI) on board MetOp since 2006. The $\mathrm{CO}_{2}$ sensitive channels of these sounders allow the determination of cloud pressure and cloud IR emissivity of the uppermost cloud layer. Bulk microphysical properties can be obtained for semi-transparent cirrus (with visible optical thickness between about 0.7 and 3.8; RÄDEL et al. (2003)) from the spectral emissivity difference in the range between 8 and $12 \mu \mathrm{m}$. These clouds constitute about half of all high clouds and a global data set of ice water path and effective particle size of these cirrus was derived from TOVS measurements on board NOAA10 (RÄDEL et al., 2003; STUBENRAUCH et al., 2004). The data set covers a time period of 4 years (from June 1987 until May 1991) and also includes information about cloud frequency and cloud temperature. It is a supplement to the longer-term (July 1987 to June 1995) TOVS Path-B data set of the frequency and pressure or temperature of total or high clouds, respectively (STUBENRAUCH et al., 2006). Long-term global cloud data are also provided by the International Satellite Cloud Climatology Project (ISCCP; Rossow and SCHIFFER, 1999). The ISCCP data has been the basis for several comparisons of global model cloud data with satellite observations (e.g., YU et al., 1996; KLEIN and JАКОВ, 1999; WEBB et al., 2001; ZHANG et al., 2005). Detailed comparisons of the ISCCP and TOVS data sets have shown that they agree quite well (JIN et al., 1996; STUBEnRAuCH et al., 1999b, 2006), with a better sensitivity of TOVS to cirrus clouds. Due to this advantage over ISCCP and due to the availability of cirrus microphysical property information, we use the TOVS data in the present study.

This article mainly aims to present the development and demonstration of a method for comparing model and satellite data. The method can easily be adapted when comparing with recent cloud climatologies from AIRS (STUBENRAUCH et al., 2008, 2010) or IASI. When extracted into a code, it could be integrated as one of the CFMIP Observational Simulator Packages (http://cfmip.metoffice.com/COSP.html). The A-Train mission (STEPHENS et al., 2002) also provides cloud measurements from two active instruments: the lidar CALIOP of the Cloud-Aerosol Lidar and Infrared Pathfinder Satellite Observations (CALIPSO) mission and the cloud profiling radar (CPR) of the CloudSat mission. CALIPSO is sensitive to very thin cirrus and CloudSat to thicker clouds. Both instruments together 
provide for the first time vertical cloud profiles along the track. However, their spatial coverage is much sparser than the one of AIRS, with one nadir-viewing orbit every $1000 \mathrm{~km}$.

Comparing cloud properties simulated by global models with satellite data requires a careful consideration of comparability aspects since such comparisons can be affected by the methodical differences between the models and the satellite measurements and data retrievals. Detailed methods have been developed for comparing modelled cloud fields with ISCCP data (YU et al., 1996; KLEIN and JAKOB, 1999). Recently also methods for using CALIPSO and CloudSat data have been made available (HAYNES et al., 2007; BODAS-SALCEDO et al., 2008; CHEPFER et al., 2008). In the present study, a new method for comparison of global cloud simulations with TOVS data was developed. Due to similarities in IR sounder data retrievals, the method is transferable for future comparisons of GCM simulations with data from other IR sounders, such as AIRS. The method takes into account the following aspects: While models calculate three-dimensional cloud fields and their continuous temporal change, the satellite measurements provide a two-dimensional view on the highest cloud layer at specific observation times. The spatial resolution of current global climate models is coarse compared to the TOVS data. Therefore, TOVS is capable to resolve cloud structures which are of subgrid-scale in the models. Another important difference is that the TOVS data do not contain information about subvisible cirrus which, in contrast, can be simulated. Furthermore, the TOVS bulk microphysical cirrus properties can only be retrieved for a specific range of cloud optical thickness (semi-transparent cirrus). To establish comparability, these discrepancies have to be taken into account. It is also important how high clouds are distinguished from lower level clouds. For reasons of comparability, high cloudiness has to be selected from the model output in a similar manner as from the satellite data. In the present study, methods were developed that aim at extracting those cloud layers from the model output that would be detected by TOVS. Such selective output of the ECHAM model applied here was then compared to the TOVS data. High and total cloudiness were distinguished. Macro- and microphysical properties, especially of cirrus clouds, were considered. As a new feature compared to the methods focusing on other satellite data, comparisons of modelled and retrieved cloud particle sizes were included.

The paper is structured as follows. Section 2 provides descriptions of the model as well as the TOVS data sets used in this study. Furthermore, the evaluation method is characterized in detail. Examples for comparing the model results with the satellite data are discussed in section 3 . In section 4 , the major conclusions are highlighted and a critical discussion of the evaluation methodology is provided.

\section{Methodology}

\subsection{Model description}

The comparison method was developed applying the ECHAM4 general circulation model (ROECKNER et al., 1996) in order to develop a standard tool for evaluating modelled cirrus properties. The method is intended to be used extensively in applications of the next generation model version ECHAM5 which is now becoming standard. Prognostic variables of ECHAM are vorticity, divergence, temperature, (logarithm of) surface pressure, water vapour and cloud water. The model includes physical parameterizations of radiation, cloud processes, precipitation, convection, diffusion, planetary boundary layer dynamics, land-surface processes as well as gravity wave drag. Here, an extended version of ECHAM4 was used including cloud microphysical and aerosol schemes (LOHMANN et al., 1999, 2004). The cloud scheme includes prognostic equations for the cloud liquid water content and the cloud droplet number concentration as well as the ice water content and the ice crystal number concentration (LOHMANN and ROECKNER, 1996; LOHMANN et al., 1999; LOHMANN, 2002). Subgrid-scale cloud cover is diagnosed from relative humidity following SUNDQVIST et al. (1989). To enable the simulation of cirrus cloud formation by aerosolinduced ice nucleation, the original saturation adjustment scheme was replaced by a new scheme that permits ice supersaturation (LOHMANN and KÄRCHER, 2002). The model version applied here for testing the evaluation methodology considers aerosol-induced ice nucleation by homogeneous freezing of supercooled solution droplets (KÄRCHER and LOHMANN, 2002). Heterogeneous nucleation (KÄRCHER and LOHMANN, 2003) of cirrus ice particles is neglected.

For the present study, a spectral transform approach with triangular truncation at zonal wave number 30 (T30) is used. This results in a nominal horizontal resolution of approximately $3.75^{\circ}$ in latitude and longitude. The model domain covers the vertical range from the surface to $10 \mathrm{hPa}$ by 19 layers characterized by a hybrid $\sigma$-p-coordinate system. A semi-implicit leap frog scheme is applied for time integration. A time step $\Delta \mathrm{t}$ of $30 \mathrm{~min}$ is used. The horizontal and vertical advection of positive definite quantities like water vapour, cloud water, or aerosol constituents is calculated applying a semi-Lagrangian scheme by WILLIAMSON and RASCH (1994). The model run analyzed here was performed for a 10 -year time period after a 15 -month model spin-up.

\subsection{TOVS Path-B data}

The TOVS system consists of two sounders: the High resolution Infrared Radiation Sounder (HIRS) with 19 infrared spectral channels between 3.7 and $15 \mu \mathrm{m}$ and one visible channel $(0.7 \mu \mathrm{m})$ and a Microwave Sounding Unit (MSU) or Advanced Microwave Sounding Unit (AMSU) since NOAA15. The TOVS Path-B data set 
(SCOTT et al., 1999) includes global atmospheric temperature and water vapour profiles as well as cloud and surface properties. The spatial resolution is $1^{\circ}$ latitude $\times 1^{\circ}$ longitude. Since the spatial resolution of the HIRS measurements is significantly higher $(\sim 17 \mathrm{~km})$, the $1^{\circ} \times 1^{\circ}$ grid data contains also subgrid-scale information, e.g. the subgrid-scale cloud coverage. The data set presently covers the 8-year time period from July 1987 to June 1995. TOVS observes cloud properties at $7 \mathrm{~h} 30$ and $19 \mathrm{~h} 30$ local time. Cloud pressure $p_{c l d}$ and effective IR cloud emissivity $\varepsilon_{c l d}$ are retrieved by a weighted $\chi^{2}$ method, using five radiances along the $15 \mu \mathrm{m} \mathrm{CO} 2$ absorption band (STUBENRAUCH et al., 1999a). Cloud pressure is transformed into cloud temperature $T_{\text {cld }}$ by using the retrieved atmospheric temperature profiles. The relatively high spectral resolution of TOVS allows a reliable identification of cirrus, day and night (e.g., WYLIE et al., 1994; STUBEnRAUCH et al., 1999a). Cloud height has been evaluated (STUBENRAUCH et al., 2005) by using vertical profiles of backscattered radiation from the quasi-simultaneous Lidar In space Technology Experiment (LITE). The cloud height determined by TOVS in general corresponds well to the height of the 'apparent middle' (see section 2.3.5) of the cloud system at $1^{\circ}$ spatial resolution. In the case of multilayer clouds, the TOVS data only give information about the highest cloud layer. These results have been confirmed by studies of STUBENRAUCH et al. (2008, 2010), comparing AIRS with CALIPSO, when AIRS cloud properties are retrieved by using the same weighted $\chi^{2}$ method. The thinnest clouds which can be detected by TOVS show visible optical thicknesses around $\tau=0.1$ (noise level of TOVS). WYLIE and MENZEL (1989) estimated $50 \%$ of cirrus with $\tau$ around 0.2 is not detected by the $\mathrm{CO}_{2}$ slicing method in the visible and infrared spin-scan radiometer atmospheric sounder (VAS) satellite data. High clouds are defined as clouds with $p_{c l d}<440 \mathrm{hPa}$, according to ISCCP. Compared to ISCCP, the TOVS Path-B cloud climatology contains more high clouds (especially in the tropics) because of the better sensitivity to thin cirrus of these instruments (STUBENRAUCH et al., 2006).

Additional efforts were made to derive bulk microphysical properties of cirrus clouds from TOVS measurements (STUBENRAUCH et al., 1999b; RÄDEL et al., 2003; STUBEnRAuCH et al., 2004). The mean effective diameter $D_{e}$ can be considered as an effective photon path of the ice crystal size distribution and is defined by Mitchell (2002) as:

$$
D_{e}=\frac{3}{2} \cdot \frac{I W C_{s}+I W C_{l}}{\rho_{i c e}\left(P_{s}+P_{l}\right)},
$$

where $\rho_{\text {ice }}$ is the bulk density of ice and is assumed to have the value of $0.92 \mathrm{~g} / \mathrm{cm}^{3}, I W C_{s}$ and $I W C_{l}$ are the ice water contents (amount of ice per volume of air), and $P_{s}$ and $P_{l}$ are the projected areas (defined as area densities), corresponding to number densities of small and large particle modes, respectively. Mean effective ice crystal diameters $D_{e}$ of cirrus clouds could be retrieved since the spectral cirrus effective emissivity difference between the 11 and $8 \mu \mathrm{m}$ channels increases with decreasing $D_{e}$. For large $D_{e}$ and opaque or very thin cirrus, the emissivities are similar. Therefore, this method is sensitive to diameters up to $80 \mu \mathrm{m}$ and can be applied to large-scale high cloudiness in the visible optical thickness range between about 0.7 and 3.8 (corresponding to IR emissivity between 0.3 and 0.85 ). These clouds are frequently termed semi-transparent cirrus (s-t ci). The ice water path (IWP; total ice mass within an air column divided by base area of the column) was then derived from the cirrus effective emissivity at $11 \mu \mathrm{m}$ and the retrieved $D_{e}$.

To transform the retrieved cirrus emissivities into $D_{e}$, look-up tables have been constructed from radiative transfer computations (KEY and SCHWEIGER, 1998) for a homogeneous ice cloud of $1 \mathrm{~km}$ thickness, with a top at $10 \mathrm{~km}$ altitude, containing planar polycrystals distributed according to a bimodal $\Gamma$-size distribution. The lapse rate is assumed as $6.5^{\circ} \mathrm{C} / \mathrm{km}$. The advantage of comparing cirrus emissivities instead of brightness temperatures is that atmospheric effects have been removed. Table 1 of RÄDEL et al. (2003) summarizes the uncertainty sources and their influence on the retrieval of $D_{e}$. Uncertainties may reach $25 \%$. These are linked to the assumptions in the retrieval. For example, $D_{e}$ may be underestimated in the case of a broader ice particle size distribution or if $D_{e}$ increases from cloud top to cloud bottom. $D_{e}$ may be overestimated when the ice crystals have the form of hexagonal columns instead of aggregates, if a low cloud is underneath or in the case of partial cloud cover.

Note, that only large-scale clouds covering full $1^{\circ} \times 1^{\circ}$ grid boxes were considered in the analysis of $D_{e}$. Data generated by this method for the three complete years (1988-1990) of the 4 year time period mentioned in section 1 are used here. These data will be referred to as the cirrus microphysics data set (CIMD).

\subsection{Comparison method}

\subsubsection{General remarks}

Several systematic differences between the TOVS data and the model output complicate a direct comparison of the two data sets. i) The TOVS observations show a higher spatial resolution than the model. While the TOVS data sets used here show a resolution of $1^{\circ}$ in longitude and latitude, the model T30 resolution corresponds to a $3.75^{\circ} \times 3.75^{\circ}$ geographical grid; ii) In contrast to the model, the TOVS data are restricted to specific cloud optical thickness ranges. In particular, TOVS is limited to the detection of clouds with an optical thickness larger than about 0.1 (visible optical thickness). Furthermore, the cirrus bulk microphysical properties are provided for high clouds in a visible optical thickness range between about 0.7 and 3.8; iii) TOVS provides no information about the vertical distribution 
of cloud layers. While the model is capable to simulate multiple vertically overlaying clouds, TOVS is restricted to detect the highest cloud with sufficient optical depth (visible optical thickness larger than $\sim 0.1$ ); iv) TOVS observes clouds at specific observation times. In contrast, the model calculates the continuous temporal change of the cloud fields. In order to establish comparability between the TOVS data and the model output, these differences have to be considered. The methodology applied here is explained in the following. It can be transferred to data from other GCM which consider concepts of subgrid-scale cloud representation similar to those applied in the ECHAM GCM and also to other satellite data sets. For example, a 6-year climatology of AIRS data (2003-2008) is available at a $1^{\circ} \times 1^{\circ}$ grid (STUBENRAUCH et al., 2010), having a spatial resolution of about $13 \mathrm{~km}$, with observations at $1 \mathrm{~h} 30$ and 13h30. IASI observations are at $9 \mathrm{~h} 30$ and $21 \mathrm{~h} 30$ with a similar spatial resolution as AIRS.

\subsubsection{Consideration of subgrid-scale cloud structures}

In the applied model, the subgrid scale cloud cover is parameterized according to SUNDQVIST et al. (1989). In particular, the cloud cover in each individual altitudinal layer of a model grid box is calculated as a function of relative humidity. It is assumed that the cloudy fraction of a grid box shows a horizontally homogeneous distribution of cloud properties in each layer. Within the layers of a model grid box, horizontally continuous and discontinuous clouds are not distinguished. Both cloud types are handled analogously. For reasons of simplicity, we will discuss an example of a horizontally continuous cloud below. Nevertheless, all methods discussed below apply analogously in cases of horizontally discontinuous cloudiness. In order to avoid misunderstandings, we will use the term 'cloud structure' instead of 'cloud' for all types of cloudiness within a grid box, including cases of horizontal discontinuity.

For sets of cloudy model layers which are vertically not separated by cloud free model layers, maximum overlap of the cloudiness of the different layers is assumed in the respective model grid box. This results in vertically continuous cloud structures ranging over several model layers. Figure 1a shows a corresponding example of a possible cloud structure within a grid box of the model. The grid box fractional coverage of such a cloud structure is calculated as:

$$
c_{j}=\max \left\{f_{k}, \ldots, f_{k+n}\right\},
$$

where $c_{j}$ is the fractional coverage of the cloud structure labelled by index $j$ and $f_{i}, i \in\{k, \ldots, k+n\}$, are the individual cloud covers of the $n+1$ cloud layers forming the structure. The top of the cloud structure is located in layer $k$. If a model grid box contains several cloud structures separated by cloud free model layers, it is a)

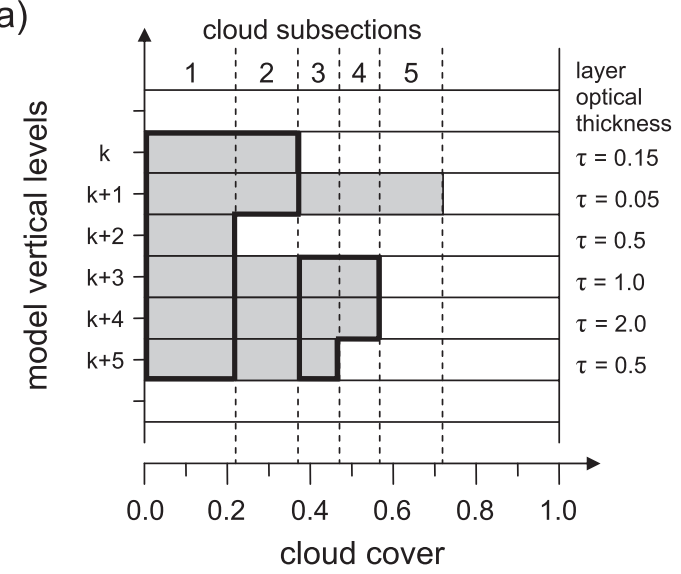

b)

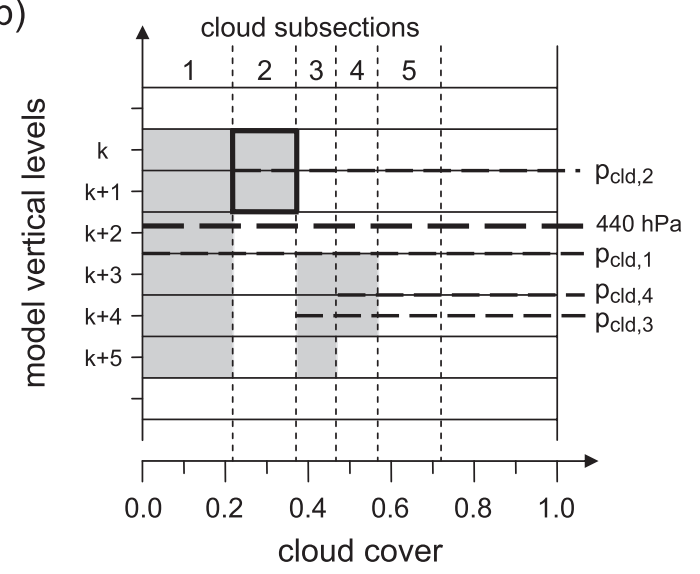

Figure 1: Schematic view of methods for comparing ECHAM cloud data with TOVS satellite observations; a) Selection of cloud layers visible for TOVS. Shaded areas correspond to the cloud layers simulated within a grid box of the model. Visible optical thickness $\tau$ as well as fractional cloud cover of each cloud layer are shown. The parts of the cloud enclosed in the thick solid lines are selected for comparison with TOVS. In cloud subsection 2, only the upper two cloud layers are selected. The highest cloud layer in subsections 3,4 , and 5 is not considered since its optical thickness is smaller than 0.1 ; b) Selection of high clouds. The thick dashed lines show the position of the height of the vertical middle of the cloudiness in the respective cloud subsection as well as the $440 \mathrm{hPa}$ level. The cloud pressure $p_{c l d, l}$ corresponds to the cloud middle height of cloud subsection $l$. Subsections selected as high cloudiness $\left(p_{\text {cld }}<\right.$ $440 \mathrm{hPa}$ ) are enclosed in thick solid lines. Only subsection 2 is selected. The presented cloud shows an optical thickness smaller than 5 . In the case of $\tau>5, p_{c l d}$ is identified with the pressure at the geometric vertical middle between the cloud top and the vertical position within the model cloud where an optical thickness of 5 is reached (see text for details).

assumed that these cloud structures overlap randomly. The total cloud coverage of the grid box is calculated as:

$$
c_{\text {total }}=1-\prod_{j}\left(1-c_{j}\right)
$$

Note that this combination of maximum and random overlap assumptions corresponds to the mixed overlap approach discussed by YU et al. (1996). 
In order to analyze the model clouds in more detail, each cloud structure is horizontally divided into subsections characterized by different vertical distributions of cloud properties (Figure 1a). This concept is also the basis of the methods for comparing global cloud simulations with ISCCP data (YU et al., 1996; KLEIN and JАКОВ, 1999). However, for the calculation of cloud properties within the subsections and for the derivation of overall cloud properties, which can be compared to the TOVS data, new approaches had to be developed which are described below. In analogy to $\mathrm{YU}$ et al. (1996), the subsections are defined here by sorting the $n+1$ layers of a cloud structure $j$ according to cloud cover. Renumbering the layers according to the new order results in:

$$
0 \leq f_{1} \leq \ldots \leq f_{n} \leq f_{n+1} \leq 1 .
$$

Each increase in cloud cover from a layer $i \in\{1, \ldots, n\}$ to an adjacent layer $i+1$ opens a new subsection $l$ with the fractional cloud coverage $s_{l}=f_{i+1}-f_{i}$. The first subsection is defined by layer 1 of the sorted system and shows the fractional cloud coverage of $f_{1}$. This definition results in $m \leq n+1$ subsections. Rearranging the cloudy layers to their original order enables the analysis of the vertical structure of cloud properties in each subsection. As shown by the example given in Figure 1, the individual vertical profiles can show different cloud top or cloud bottom altitudes. Interruptions by cloud free layers can occur. In order to mark cloud free gaps in the vertical profile of a subsection, we introduce the weight factor $w_{i l}$ for each layer $i \in\{k, \ldots, k+n\}$ of subsection $l \in\{1, \ldots, m\}$ which is set to 0 or 1 depending on whether a gap occurs or not. It can now be analyzed which cloud properties would be detected by the satellite-based sensors in the individual cloud subsections.

\subsubsection{Cloud optical thickness and effective diameter}

The visible optical thickness $\tau_{i}$ of the clouds within an individual model layer $i$ is calculated as (ROECKNER et al., 1996):

$$
\begin{aligned}
\tau_{i} & =1.91 \cdot I W C_{i} \Delta z_{i} \cdot\left(0.5 \cdot D_{e, i}^{i c e}\right)^{-1.03} \\
& +1.87 \cdot L W C_{i} \Delta z_{i} \cdot\left(0.5 \cdot D_{e, i}^{l i q}\right)^{-1.08}
\end{aligned}
$$

where $I W C_{i}$ and $L W C_{i}$ are the ice and liquid water contents (amount of cloud water per volume of air, in $\mathrm{g} / \mathrm{m}^{3}$ ) and $D_{e, i}$ (in $\mu \mathrm{m}$ ) are the effective ice crystal (superscript $i c e$ ) and liquid droplet (superscript $l i q$ ) diameters simulated for layer $i$. Furthermore, $\Delta z_{i}$ (in $\mathrm{m}$ ) is the geometric thickness of the layer. TOVS does not distinguish between frozen and liquid cloud particles. Hence, ice crystals and liquid droplets as well as possible mixtures of both particle types have to be considered in the model output. The effective diameters of the ice crystals and cloud droplets are calculated from the sizes of volume equivalent spheres as described by LOHMANN (2002) and LOHMANN et al. (1999), respectively, considering the amount of cloud ice and liquid water as well as the ice crystal and cloud droplet number concentrations calculated by the model. To calculate $D_{e, i}^{i c e}$, LOHMANN (2002) apply the empirical formulation:

$$
D_{e, i}^{i c e}[\mu m]=2 \cdot\left(1.61 \cdot r_{v, i}^{3}+3.56 \cdot 10^{-4} \cdot r_{v, i}^{6}\right)^{1 / 3}
$$

where $r_{v, i}$ (in $\mu \mathrm{m}$ ) is the volume equivalent radius of the ice particles within layer $i$ which is calculated as:

$$
r_{v, i}[\mu m]=10^{6} \cdot\left(\frac{3 I W C_{i}}{4 \pi \rho_{i c e} N_{i}^{i c e}}\right)^{1 / 3}
$$

where $\rho_{i c e}$ is the density of ice (assumed as $925 \mathrm{~kg} / \mathrm{m}^{3}$ ) and $I W C_{i}$ (in $\mathrm{kg} / \mathrm{m}^{3}$ ) and $N_{i}^{i c e}$ (in particles $/ \mathrm{m}^{3}$ ) are the ice water content and ice particle number concentration of layer $i$.

Note that the formulations to calculate cloud optical thickness and effective diameters from the model output are chosen according to the standard formulations used in the version of the ECHAM model applied here. These formulations can be exchanged, for instance, when a different GCM is applied or the sensitivity of the comparison with the observations to alternative formulations needs to be investigated.

\subsubsection{Cloud vertical structure}

The total optical thickness $\tau_{c o l}$ of a cloud column formed by a set of vertically contiguous cloudy model layers occurring within a subsection $l$ of a cloud structure $j$ can be calculated by the sum of the optical thicknesses of the individual cloudy model layers. Since the TOVS instruments are only sensitive for detecting clouds with a visible optical thickness larger than approximately 0.1 , cloud columns with $\tau_{c o l}<0.1$ are taken out of the model output. In the case of multilayered cloud systems (vertically separated overlapping clouds), TOVS determines the properties of the highest detectable cloud (visible optical thickness larger than $\sim 0.1$ ). Therefore, we also neglect all cloud layers of a subsection which are located below a cloud column with $\tau_{c o l} \geq 0.1$ and which are vertically separated from this column. Hence, only the uppermost cloud column with $\tau_{c o l} \geq 0.1$ is considered for comparison with the TOVS data. To this end, the weight factor $w_{i l}$ of each cloudy model layer $i$ of this cloud column is set to 1 while the weight factors of all other cloud layers of the subsection $l$ are set to 0 . In the example shown in Figure 1 also the optical thicknesses of the individual cloud layers are shown (Figure 1a). All cloud layers which would be considered for the comparison with the TOVS data set in the case of this example are surrounded by thick lines. If a subsection contains only cloud columns with $\tau_{c o l}<0.1$, as subsection 5 in the example, the subsection is neglected. All layers of this subsection have the weights $w_{i l}=0$. Additionally, 
it is assumed that the subsection does not contribute to cloud coverage. This is realized by setting its fractional cloud coverage $s_{l}=0$.

\subsubsection{Selection of high clouds}

Clouds are selected as high clouds when $p_{\text {cld }}<440 \mathrm{hPa}$. As mentioned in section 2.2, a comparison with LITE data has shown that the cloud pressure $p_{c l d}$ determined by the TOVS Path-B retrieval mostly corresponds to the 'apparent middle' of the cloud. 'Apparent middle' means the middle of the cloud as seen by space lidar. Here one has to consider that the laser beam passes through a cloud only up to an optical thickness of about 5 (WINKER et al., 2003). In order to establish comparability, high clouds are selected in a similar manner from the cloud fields simulated by the model. To this end, $p_{c l d}$ is identified with the pressure at the geometric vertical middle between the cloud top and the vertical position within the model cloud where an optical thickness of 5 is reached. If the model cloud shows an optical thickness below $5, p_{\text {cld }}$ is identified with the exact geometric middle. In this manner, $p_{c l d}$ is determined for the cloud columns selected as described above in each subsection of a model cloud structure. In the example shown in Figure $1 \mathrm{~b}$, high cloudiness is selected only for subsection 2 .

\subsubsection{Observation time windows}

TOVS observes cloud properties at 7h30 and 19h30 local time. Hence, clouds are extracted at corresponding local times from the model output. The coarse temporal resolution of the model $(\Delta t=30 \mathrm{~min})$ results in a significant uncertainty in the temporal structure of the diurnal variation of cloud properties. To reduce this effect in the model output, cloud properties averaged over an extended time window are considered rather than the exact points in time of the observations. We consider a time window of 3 hours with the exact observation time $t_{o b s}$ as centre, i.e. $\left[t_{o b s}-3 \Delta t, t_{o b s}+3 \Delta t\right]$. To assess the effects of this time selection, we also analyzed diurnal mean values of all cloud properties extracted from the model output.

\subsubsection{Calculation of grid-box mean cloud properties}

By the analysis described above, those subsections of a modelled cloud structure are selected which probably would be detectable for TOVS. From the cloud properties of the selected subsections, overall properties of the respective cloud structure can be calculated. The properties of the cloud structures of a respective model grid box can then be translated into overall cloud properties of the grid box which can be compared with the TOVS data. For the analysis of high cloudiness, all subsections $l \in\{1, \ldots, m\}$ with $p_{c l d} \geq 440 \mathrm{hPa}$ have to be excluded from these calculations by setting $s_{l}=0$ in the respective cloud structure. Analogously, for comparison with the TOVS microphysical data set (CIMD), only those subsections which contain high clouds within the optical thickness range $0.7 \leq \tau_{\text {col }} \leq 3.8$ (semi-transparent cirrus) have to be considered. Note that no special technique was applied to take into account that only larger scale clouds covering full $1^{\circ} \times 1^{\circ}$ grid boxes were considered in the TOVS CIMD data set. Clouds of that extension are of sub-grid scale in the coarse model grid and sub-grid scale cloud heterogeneity is not subject of the model predictions. Therefore, the amount of continuous model clouds covering $1^{\circ} \times 1^{\circ}$ areas cannot be determined.

The total fractional coverage $c_{j}$ of a cloud structure $j$ within a grid box is calculated as:

$$
c_{j}=\sum_{l=1}^{m} s_{l},
$$

where $m$ is the number of subsections. Recall that $s_{l}$ can also be zero in the case of optically too thin cloudiness $\left(\tau_{c o l}<0.1\right)$ occurring in the respective subsection. The mean cloud water path $\overline{C W P}_{j}$ of a cloud structure $j$ with $c_{j}>0$ is calculated as:

$$
\overline{C W P}_{j}=\frac{1}{c_{j}} \cdot \sum_{l=1}^{m}\left(s_{l} \cdot \sum_{i=k}^{k+n}\left(w_{i l} \cdot C W C_{i} \cdot \Delta z_{i}\right)\right),
$$

where $C W C_{i}=I W C_{i}+L W C_{i}$ denotes the cloud water content of layer $i \in\{k, \ldots, k+n\}$. For the derivation of an effective cloud particle diameter $D_{e, i}$ representative for the cloudiness within an individual cloudy model layer $i$, the information about $D_{e, i}^{i c e}$ and $D_{e, i}^{l i q}$ have to be combined in the case of mixed-phase clouds. To this end, we follow a linear combination approach:

$$
D_{e, i}=\frac{\tau_{i}^{i c e} D_{e, i}^{i c e}+\tau_{i}^{l i q} D_{e, i}^{l i q}}{\tau_{i}^{i c e}+\tau_{i}^{l i q}}
$$

Here $\tau_{i}^{i c e}$ and $\tau_{i}^{l i q}$ are the individual optical thicknesses of cloud ice and liquid water, calculated according to the respective addends of the right hand side of Eq. (2.5) $\left(\tau_{i}=\tau_{i}^{i c e}+\tau_{i}^{l i q}\right)$. The application of Eq. (2.10) results in a $D_{e, i}$ which is consistent with the total cloud optical thickness $\tau_{i}$ and the total cloud water path $C W P_{i}$ of the layer $i$, since $\tau \sim C W P / D_{e}$ is a good approximation (Eq. (2.5)). From $D_{e, i}$ the mean effective particle size of the cloud structure $j$ is calculated in analogy to Eqs. (2.9) and (2.10):

$$
\overline{D_{e, j}}=\frac{1}{c_{j}} \cdot \sum_{l, s_{l}>0}\left(s_{l} \cdot \frac{\sum_{i=k}^{k+n}\left(w_{i l} \tau_{i} \cdot D_{e, i}\right)}{\sum_{i=k}^{k+n}\left(w_{i l} \tau_{i}\right)}\right) .
$$

If more than one cloud structure occurs within a model grid box, these cloud structures reside at different altitudes and are vertically not connected. It is assumed that the different cloud structures overlap randomly (see section 2.3.2). For the comparison with the TOVS data 
sets, only those fractions of a cloud structure are considered which are not covered by other cloud structures located at higher altitudes and thus which would be visible for TOVS. The total cloud coverage $c_{\text {total }}$ of a grid box with clouds detectable for TOVS can be calculated from Eqs. (2.3) and (2.8). Semi-transparent cirrus clouds can be covered by clouds of other optical thickness. Hence, the total coverage $c_{\text {total }}$ by this cloud type has to be calculated in a different manner:

$$
c_{\text {total }}=c_{1}+\sum_{j=2}^{N}\left(c_{j} \cdot \prod_{i=1}^{j-1}\left(1-c_{t i}\right)\right),
$$

where $N$ is the total number of cloud structures which are ordered by decreasing cloud altitude, i.e. indices 1 and $N$ represent the highest and lowest cloud structure, respectively. $c_{1}$ and $c_{j}$ are the contributions of semitransparent cirrus to the individual cloud coverage of cloud structures 1 and $j . c_{t i}$ is the total coverage of cloud structure $i$ detectable for TOVS, i.e., $c_{t i}$ is the sum of the cloud cover contributions of all cloud columns of structure $i$ with $\tau_{c o l} \geq 0.1$. The corresponding grid box representative value $X_{\text {total }}$ of other cloud related quantities, particularly $C W P$ or $D_{e}$, is calculated from the values $\bar{X}_{j}$ of the different cloud structures as:

$$
X_{\text {total }}=\frac{1}{c_{\text {total }}}\left(c_{1} \bar{X}_{1}+\sum_{j=2}^{N}\left(c_{j} \bar{X}_{j} \cdot \prod_{i=1}^{j-1}\left(1-c_{t i}\right)\right)\right) .
$$

Note that Eqs. (2.12) and (2.13) can also be used analogously to calulate $X_{\text {total }}$ of other cloud types, such as high cloudiness, by using the corresponding values of $c_{j}$.

\section{Exemplary results}

In the following, exemplary results obtained with the comparison method described above are presented. We use the term 'selected' for the cloud fields extracted from the model output with this new method. Particularly the effects of its application are discussed in this section.

Figure 2 shows the latitudinal variation of the mean cloud frequencies derived from the model output and the satellite measurements. The cloud frequencies represent annual and zonal averages of the local cloud coverage. Figure 2a shows the total cloud frequency. 'Selected clouds' means in this case clouds with a visible optical thickness larger than 0.1 . The results reveal that the selection reduces the total cloud frequency slightly in the tropics and has no effect in the other regions. This would be expected since subvisible cirrus is most frequent in the tropics (WINKER and TREPTE, 1998). The restriction of selecting only data from the observation time windows at $7 \mathrm{~h} 30 \mathrm{AM}$ and PM local time has a negligible effect. In comparison to the TOVS data (red curve) the model shows significantly smaller total cloud frequencies between $45^{\circ} \mathrm{N}$ and $45^{\circ} \mathrm{S}$. Note that a)

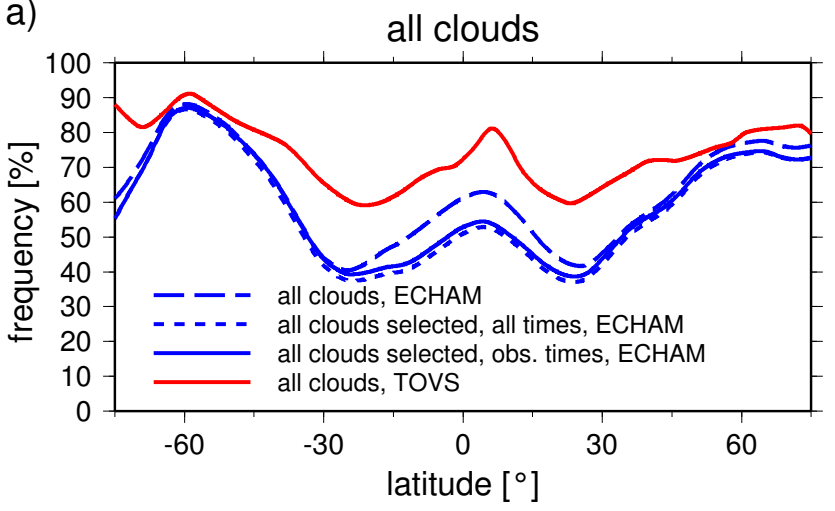

b)
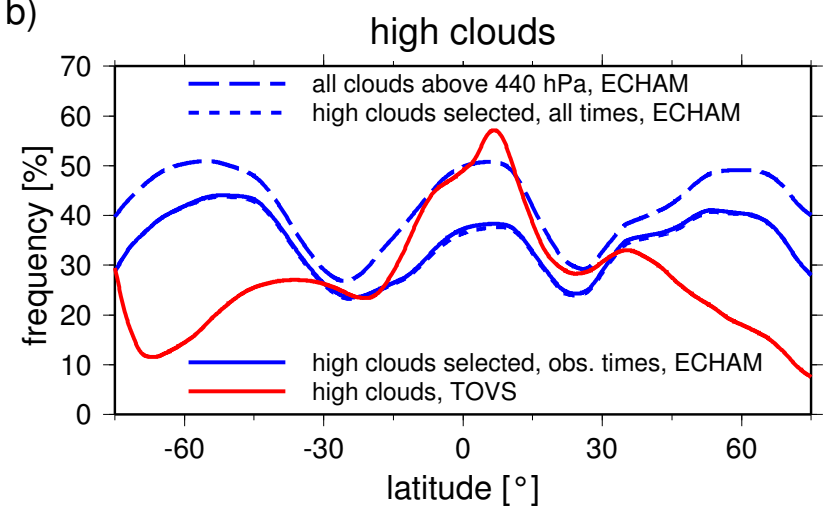

Figure 2: Annual and zonal mean cloud frequency according to ECHAM4 and TOVS Path-B data. a) The total cloudiness is considered. The curves represent the frequency of all clouds simulated considering all daytimes (long-dashed curve), all model clouds selected for comparison with TOVS considering all daytimes (shortdashed curve), all model clouds selected by considering observation time windows only (solid blue curve), and all clouds detected by TOVS (solid red curve). b) as a) but for high cloudiness only. Note that 'all clouds above $440 \mathrm{hPa}$ ' (long-dashed curve) represents all model cloudiness located above the $440 \mathrm{hPa}$ level, independent on the position of the cloud middle. The cloud frequencies shown here represent annual and zonal averages of the local cloud coverage. See text for more details.

the total cloud amount retrieved from ISCCP observations (not shown) is slightly smaller compared to TOVS (STUBENRAUCH et al., 2006). Nevertheless, also the ISCCP data reveals larger total cloud frequencies than the model. CALIPSO measurements, being sensitive even to subvisible cirrus, lead to a total cloud amount which is about $10 \%$ larger than the one retrieved from AIRS and TOVS Path-B (STUBENRAUCH et al., 2008, 2010).

The effect of the cloud selection is larger when only high clouds are considered. In Figure $2 b$ the frequency of all high model clouds is shown (long-dashed curve). All model cloud layers located above the $440 \mathrm{hPa}$ level were considered for this analysis. All cloud layers below $440 \mathrm{hPa}$ were neglected. Figure $2 \mathrm{~b}$ also presents the frequency of high clouds obtained with the selection method (solid and short-dashed blue curves). The cloud selection results in a significant reduction in the frequency of high clouds in the tropics and a smaller 
reduction in the midlatitudes. This is expected as explained above. In addition, the method for selecting high clouds can contribute to the frequency reduction. Since $p_{c l d}$ is averaged over the cloud top and the layer at which the cloud reaches a visible optical thickness of 5, cloud columns with $p_{c l d} \geq 440 \mathrm{hPa}$ are not taken into account even if the upper layers of these columns reach levels above $440 \mathrm{hPa}$. As in the case of total cloud frequency, the consideration of the particular observation time windows has a negligible effect on the annual zonal mean frequency of selected high cloudiness. Whereas the TOVS Path-B data (red curve) (and other data sets not shown) show a larger frequency of high clouds in the tropics (linked to the intertropical convergence zone (ITCZ)) than in the other regions, the model shows as much high clouds at midlatitudes as in the tropics. The selection method improves the comparison results at midlatitudes but significantly increases the discrepancies in the tropics where the model shows smaller high cloud frequencies than the observations. This indicates that probably the tropical high clouds are optically too thin. In the midlatitudes where there are too many high clouds in the model, the use of a cloud coverage parameterization which has not yet been adapted to the cloud microphysics scheme can be an important reason for some of the discrepancies (LOHMANN and KÄRCHER, 2002).

Figure 3 shows global distributions of the frequency of s-t ci clouds (high clouds with a visible optical thickness of $0.7 \leq \tau \leq 3.8$ ). Model results extracted with the selection method (top) and TOVS data from the microphysical data set CIMD (bottom) are presented. Note that the TOVS CIMD data were transformed to the model grid to facilitate the comparison. Again, the ITCZ does not appear well in the model. Figure 4a shows the zonal mean frequencies of the s-t ci clouds. These can be easily compared with the zonal mean frequencies of all selected high clouds $(\tau \geq 0.1)$ shown in Figure $2 \mathrm{~b}$. It turns out that, in both the model and the satellite data, the frequency of the s-t ci clouds is significantly smaller than the total high cloud frequency. This clearly shows that model cloud selection by optical depth is essential for comparisons with the TOVS microphysical data set.

Figure $4 \mathrm{~b}$ presents the annual zonal mean cloud water path (CWP) of the s-t ci clouds according to the model output (solid blue curve) and the TOVS CIMD data (solid red curve). Only the cloudy periods were taken into account to calculate the mean CWP. Therefore, the comparison between modelled and observed CWP is not affected by the deviations in cloud frequencies discussed above. The TOVS observations show a slightly larger CWP of s-t ci clouds than the model. Maximum deviations occur in the tropics where the observed values are about a factor of 1.5 larger. In the TOVS retrieval the ice water path in s-t ci clouds is derived from the cirrus effective emissivity at $11 \mu \mathrm{m}$ and the retrieved $D_{e}$ applying simulated look-up tables. These look-up tables show quasi-linear relationships between IWP and

\section{semi-transparent cirrus}

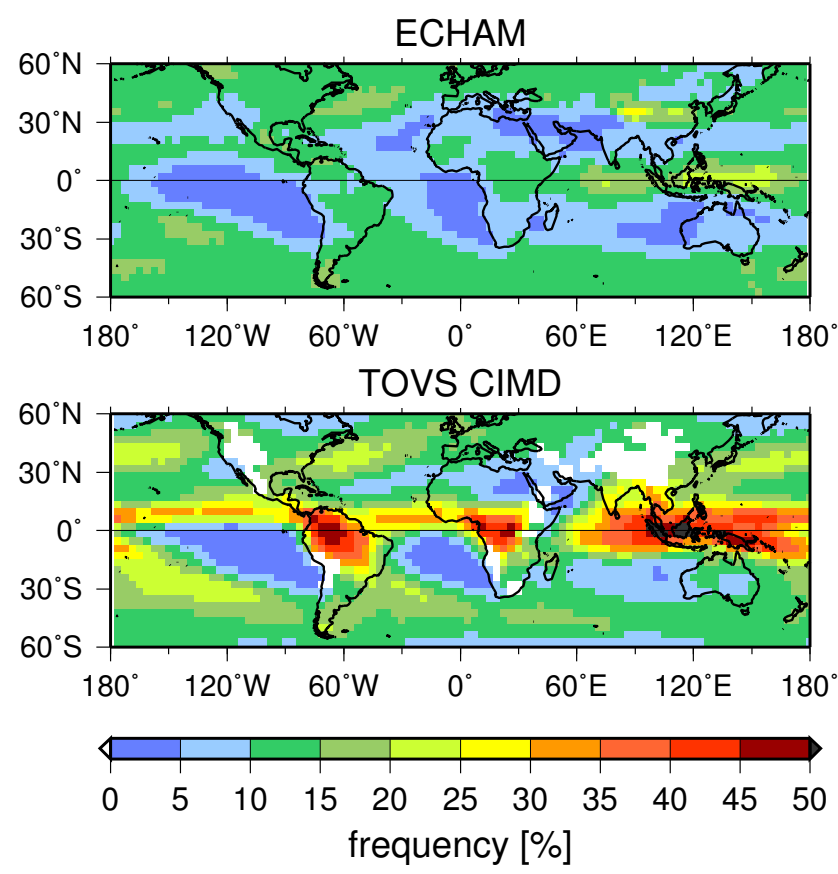

Figure 3: Annual mean horizontal distributions of the frequency of semi-transparent cirrus (high clouds with a visible optical thickness of $0.7 \leq \tau \leq 3.8$ ). The plots show ECHAM4 data selected for comparison with TOVS (top) as well as the corresponding data from the TOVS cirrus microphysics data set CIMD (bottom). The cloud frequencies shown here represent annual averages of the local cloud coverage. The TOVS data were transformed to the model grid for reasons of comparability. For white coloured areas, no data are available.

$D_{e}$ for a given emissivity (STUBENRAUCH et al., 2004). Hence, the uncertainties of up to $25 \%$ in the retrieved $D_{e}$ discussed in section 2.2 also apply to the ice water path. Such uncertainties can affect the comparison with the model data. For instance, varying the assumptions on crystal shape in the retrieval can lead to a better agreement of model and observations while assuming a broader ice particle size distribution would lead to even larger discrepancies.

Figure $4 \mathrm{~b}$ also shows the CWP of all high clouds selected from the model output (dashed blue curve). It is a factor of 3-6 higher than the CWP of the modelled s-t ci clouds which, probably, is an effect of the large CWP of clouds with $\tau>3.8$. This emphasizes the importance of the s-t ci cloud selection. The separation of the s-t ci clouds results in a much better resemblance of the CWP with the TOVS data. Recently, high cloud IWP data from the first year of the CloudSat mission became available (AUSTIN et al., 2009; WU et al., 2009). The general features of the global IWP distributions gained from these data seem to be consistent with the TOVS data. Nevertheless, longer-term data are required and comparability aspects have to be taken into account for a quantitative comparison. The simulated global distribu- 
a) cirrus frequency
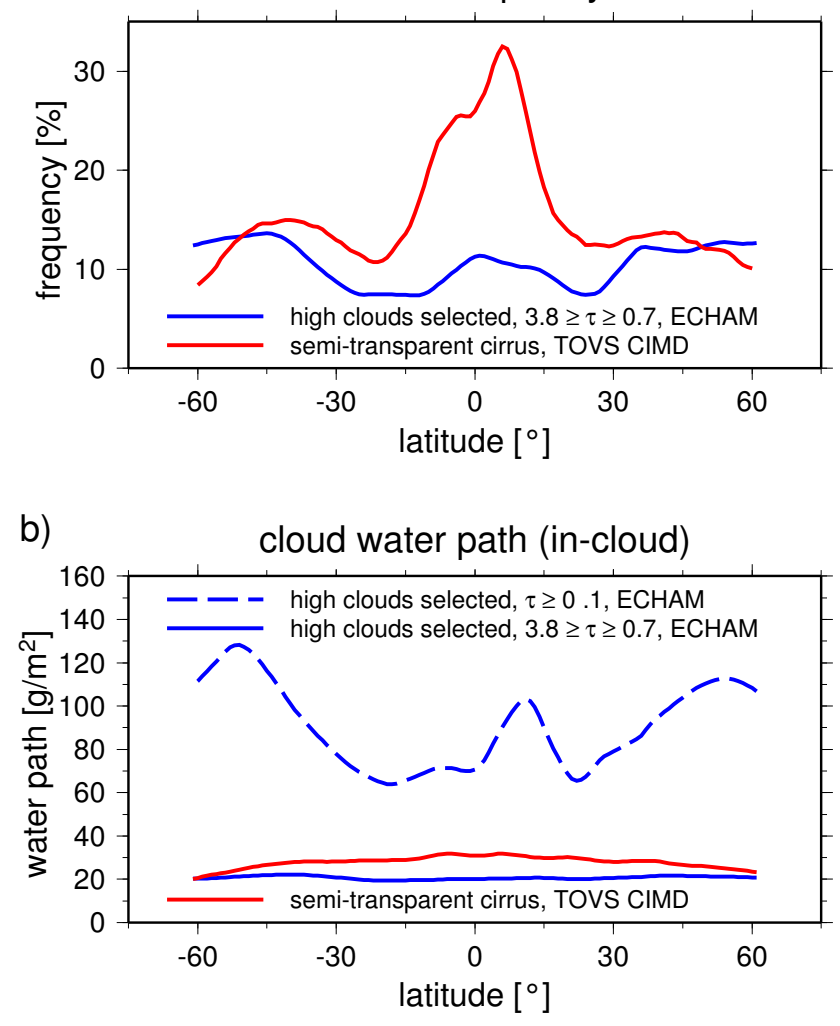

Figure 4: Annual and zonal mean frequency (a) and cloud water path (b) of semi-transparent cirrus (high clouds with a visible optical thickness of $0.7 \leq \tau \leq 3.8$ ). The plots show ECHAM4 data (solid blue curves) selected for comparison with the TOVS cirrus microphysics data set CIMD (solid red curves). The mean cloud water path was calculated from the in-cloud values only, which means that cloud free areas were not considered for calculating averages. The dashed curve in Figure $b$ shows the cloud water path of all high clouds $(\tau \geq 0.1)$ selected for comparison with the TOVS data.

tions of cloud water content can also be compared with satellite data from the Microwave Limb Sounder (MLS) (WATERS et al., 1999; Wu et al., 2006, 2009). In agreement with the results discussed above, the MLS data mostly shows more cloud water than the model, with largest discrepancies in the tropics and only small differences at midlatitudes (not shown).

Figure 5 shows the frequency distribution of the mean effective cloud particle diameter of high clouds according to the model output and the TOVS measurements. In particular, the number of model grid points showing an annual mean effective diameter within a specific size range is plotted. To this end, the TOVS data were transformed to the models T30 grid. Figure 5a shows the frequency distribution obtained for the s-t ci clouds selected from the model output and the corresponding TOVS CIMD data. While the observed $D_{e}$ show a bimodal frequency distribution, the simulation results reveal a single mode only. This mode, however, matches the observed smaller particle mode reasonably well. The larger particle mode of the observations is mainly at-
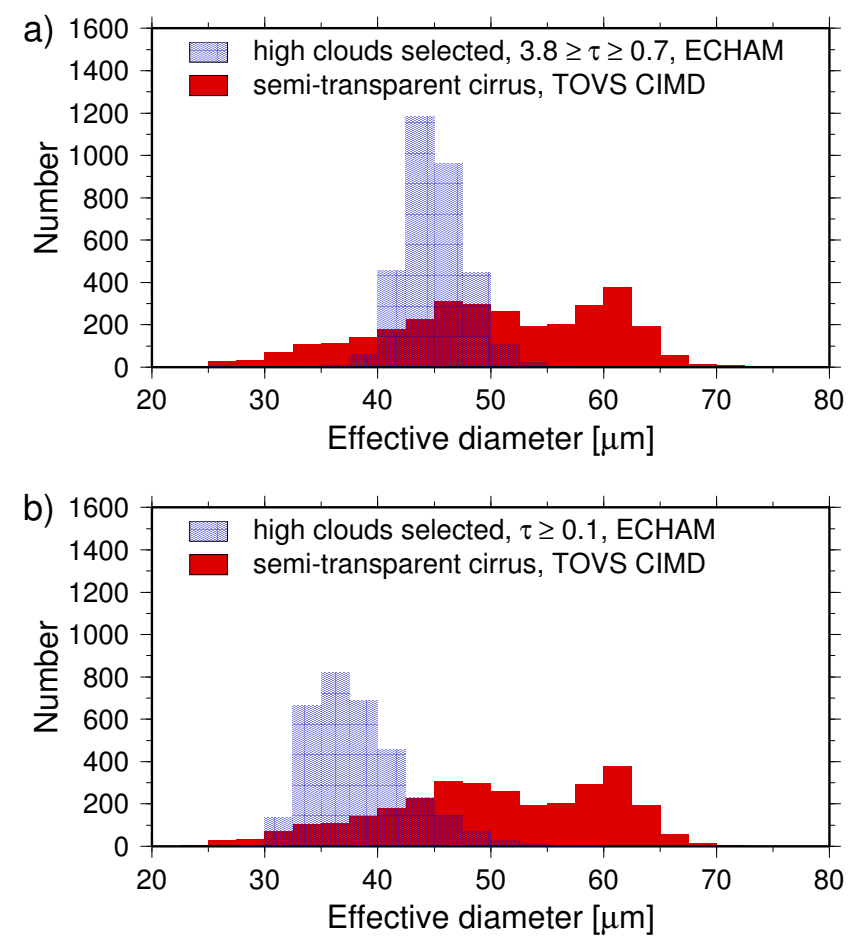

Figure 5: Frequency distributions of the mean effective cloud particle diameter in high clouds as derived from the TOVS cirrus microphysics data set (red) and from the model output (blue) selected for comparison with the TOVS data. The plots show the number of model grid points located between $60^{\circ} \mathrm{N}$ and $60^{\circ} \mathrm{S}$ showing an annual mean effective particle diameter within a specific size range (width of the bars). The TOVS data were transformed to the model grid for reasons of comparability. Model results obtained for high clouds in the visible optical thickness range of $0.7 \leq \tau \leq 3.8$ (a) and corresponding results obtained for all selected high clouds with $\tau \geq 0.1$ (b) are presented.

tributed to observations at tropical latitudes. A possible reason for the lack of this mode in the model results could be that the model shows smaller cloud water paths in the tropics (Figure 4b) which could result in reduced particle sizes (see also STUBENRAUCH et al. (2007)). Another reason could be that the microphysical cloud scheme applied in the model generates too many ice particles, particularly in the tropics. This could result from uncertainties in the representation of the subgrid-scale updraft velocity which is one of the key parameters driving the number of nucleating ice particles in the model. As in the case of the cloud water path, the comparison of modelled and retrieved $D_{e}$ can also be affected by retrieval uncertainties (section 2.2). For instance, assuming hexagonal columns instead of aggregates for tropical cirrus in the retrieval would lead to a much better resemblance with the model data. However, other possible modifications, as the assumption of a broader tropical ice particle size distribution would enlarge the discrepancies. The model implicitly considers specific ice crystal shapes and sizes by applying an empirical formulation to calculate the effective diameter (section 2.3.3). 
This can also be a source of uncertainty since this formulation might be inconsistent with the corresponding assumptions in the retrieval. Hence, for future applications of the method developed here, we recommend additional calculations considering the same crystal habits in the model and the retrieval to avoid a systematic bias.

Figure $5 \mathrm{~b}$ again shows the retrieved $D_{e}$ frequency distribution but presents the $D_{e}$ distribution derived from the model data by taking into account all selected high clouds $(\tau \geq 0.1)$. This distribution is in worse agreement with the observations since the modelled $D_{e}$ are shifted towards smaller values. This again demonstrates that the selection of s-t ci clouds is of crucial importance.

\section{Discussion and conclusions}

A methodology was developed to compare the cloudiness simulated by the ECHAM GCM with a cloud climatology retrieved from measurements by the satellitebased TOVS sensors. The basic idea of the method is to select clouds from the GCM output which would be detected by the satellite instruments and for which cirrus bulk microphysical properties are retrieved. To this end, cloud optical thickness, cloud height, and possible subgrid scale variability of cloudiness are analyzed. The data are selected for the specific observation time windows of the satellite. Particular emphasis is placed on the treatment of cloud microphysical properties, such as cloud water path and effective particle size. The method can be transferred to data from other GCM which consider concepts of subgrid-scale cloud representation similar to those applied in the ECHAM GCM and also to other IR sounder data sets.

Application of the method to ECHAM simulations reveals that the cloud selection has a marginal effect on the analysis of the frequency of total cloudiness. It is, however, highly relevant in the case of high cloudiness. The frequency of the selected high clouds is significantly smaller than the overall frequency of high cloudiness in the simulation. Largest reductions in the frequency of high cloudiness occur around the equator and amount to about $30 \%$ (relative change). The cloud selection is highly important when cloud microphysical properties obtained by the model are compared to the TOVS cirrus microphysics data (CIMD). In this case, frequency, cloud water path, and mean effective particle diameter of high clouds with a visible optical thickness of $0.7 \leq \tau \leq 3.8$ (semi-transparent cirrus) were analyzed. The restriction to this cloud type has a large effect. Extracting cloud properties for all selected high clouds and for selected high clouds within the specific optical thickness range leads to very different results. The selection according to the specific optical thicknesses results in a reduction of the mean cloud water path by factors of more than 3 as compared to the case where all optical thicknesses larger than 0.1 are considered. Furthermore, restricting the optical thicknesses according to semitransparent cirrus causes a significant increase in the mean effective cloud particle diameter. These changes reduce differences between the simulation and the observations. Therefore, a careful cloud selection by optical thickness appears to be essential for a proper comparison of the model results with the observations. It is also very important that the method to select high cloudiness from the model output is consistent with the approach followed in the satellite data retrieval. The restriction on model results obtained for the specific local satellite observation time windows is of secondary importance for the comparisons discussed above.

The results discussed in section 3 indicate several discrepancies between the model simulations and the TOVS data. In particular, the frequency of extratropical high clouds is larger in the model than observed by TOVS. In the tropics, the model shows significantly lower frequencies of high cloudiness. The cloud water path of semi-transparent cirrus clouds is smaller in the model than in the TOVS CIMD data set. Also the mean effective cloud particle diameter of this cloud type is smaller in the simulations, particularly at tropical latitudes. Any interpretation of these discrepancies in terms of a model evaluation should be carefully considered. It should be taken into account that uncertainties are inherent not only in the model but also in the satellite data retrievals. Variations of assumptions applied in the retrievals, for instance on crystal habits and size distributions, can have a significant effect on the retrieved quantities. To reduce systematic biases between model and observations, assumptions applied in the model, for instance, to calculate effective diameters, should be consistent with the retrieval. In addition, also other types of observations, such as in-situ or ground-based measurements or even other types of satellite data should be subject of a proper evaluation process. The comparison results presented in section 3 are only examples to demonstrate the method developed here. In future applications, many other parameters, such as cloud temperature or pressure, could be analyzed. Also correlations between, for instance, IWP, $D_{e}$, and cloud temperature (STUBENRAUCH et al., 2004), as represented by the satellite data and the model could be considered. Seasonal cycles could be compared, in addition to spatial distributions.

Large efforts have been made here to obtain comparability between climate model output and the results of the satellite cloud data retrievals. The subjects of the comparison have been cirrus cloud properties as simulated by the model and retrieved from the satellite observations. Alternatively, the comparison could have been performed on the basis of a satellite simulator which calculates those radiation parameters from the model output which are directly measured by the satellite along its flight track. These simulated satellite data would be directly comparable to the measurements. However, such an approach mostly is too expensive for operational application in climate models, due to comparatively high computational expenses of radiative transfer schemes. 
Furthermore, we are particularly interested in evaluating simulated microphysical cloud parameters. Such an evaluation requires the use of derived satellite data products, rather than the directly measured radiation parameters.

\section{Acknowledgments}

The authors thank K. GIERENS, O. KRÜGER, U. LOHMANN, M. PONATER, and R. SAUSEN for helpful discussions. This research was performed within the DLR/HGF (Helmholtz Gemeinschaft Deutscher Forschungszentren) project 'Particles and Cirrus Clouds' (PAZI-2) and the DLR project 'Climate-compatible air transport system' (CATS). The model was operated at the German Climate Computing Centre (DKRZ, Hamburg, Germany). The TOVS Path-B data set has been processed at IDRIS, the computer centre of C.N.R.S.

\section{References}

Aumann, H.H., M.T. Chahine, C. Gautier, M.D. GoldberG, E. Kalnay, L.M. McMillin, H. ReVERCOMB, P.W. Rosenkranz, W.L. SMITH, D.H. Staelin, L.L. Strow, J. Susskind, 2003: AIRS/AMSU/HSB on the Aqua mission: design, science objectives, data products, and processing systems. - IEEE Trans. Geosci. Remote Sens. 41, 253-264, DOI:10.1109/TGRS.2002.808356.

Austin, R.T., A.J. Heymsfield, G.L. Stephens, 2009: Retrieval of ice cloud microphysical parameters using the CloudSat millimeter-wave radar and temperature. - J. Geophys. Res. 114, D00A23, DOI:10.1029/2008JD010049.

Bodas-SAlcedo, A., M.J. WebB, M.E. BRoOKS, M.A. Ringer, K.D. William, S.F. Milton, D.R. WilSON, 2008: Evaluating cloud systems in the Met Office global forecast model using simulated CloudSat radar reflectivities. - J. Geophys. Res. 113, D00A13, DOI:10.1029/2007JD009620.

Chen, T., W.B. Rossow, Y. ZHANG, 2000: Radiative effects of cloud-type variations. - J. Climate 13, 264-286.

Chepfer, H., S. BONy, D. Winker, M. Chiriaco, J.L. Dufresne, G. SÈze, 2008: Use of CALIPSO lidar observations to evaluate the cloudiness simulated by a climate model. - Geophys. Res. Lett. 35, L15704, DOI:10.1029/2008GL034207.

HAYNES, J.M., R.T. MARCHAND, Z. LUO, A. BODASSAlCEDO, G.L. STEPHENS, 2007: A multi-purpose radar simulation package: QuickBeam. - Bull. Amer. Meteor. Soc. 88, 1723-1727.

JiN, Y., W.B. Rossow, D.P. WyLIE, 1996: Comparison of the climatologies of high-level clouds from HIRS and the ISCCP. - J. Climate, 9, 2850-2879.

KÄRCHER, B., U. LOHMANN, 2002: A Parameterization of cirrus cloud formation: Homogeneous freezing including effects of aerosol size. - J. Geophys. Res. 107(D23), 4698, DOI:10.1029/2001JD00 1429.

—, - 2003: A Parameterization of cirrus cloud formation: Heterogeneous freezing. - J. Geophys. Res. 108(D14), 4402, DOI:10.1029/2002JD003220.

KEY, J., A. SCHWEIGER, 1998: Tools for atmospheric radiative transfer: Streamer and FluxNet. - Computer \& Geosciences. 24, 443-451.
KLEIN, S.A., C. JAKOB, 1999: Validation and sensitivities of frontal clouds simulated by the ECMWF model. - Mon. Weather Rev. 127, 2514-2531.

LIOU, K.-N., 1986: Influence of cirrus clouds on weather and climate processes: A global perspective. - Mon. Weather Rev. 114, 1167-1199.

LoHMAnN, U., 2002: Possible aerosol effects on ice clouds via contact nucleation. - J. Atmos. Sci. 59, 647-656.

LOHMANN, U., J. FeICHTER, 2005: Global indirect aerosol effects: a review. - Atmos. Chem. Phys. 5, 715-737.

LOHMANN, U., B. KäRCHER, 2002: First interactive simulations of cirrus clouds formed by homogeneous freezing in the ECHAM GCM. - J. Geophys. Res. 107(D10), 4105, DOI:10.1029/2001JD000767.

LOHMAnN, U., E. RoECKNER, 1996: Design and performance of a new cloud microphysics scheme developed for the ECHAM general circulation model. - Climate Dynam. 12, 557-572.

Lohmann, U., J. Feichter, C.C. Chuang, J.E. PenNER, 1999: Predicting the number of cloud droplets in the ECHAM GCM. - J. Geophys. Res. 104, 9169-9198.

LOHMANN, U., B. KÄRCHER, C. TIMMRECK, 2003: Impact of the Mt. Pinatubo eruption on cirrus clouds formed by homogeneous freezing in the ECHAM GCM. - J. Geophys. Res., 108(D18), 4568, DOI:10.1029/2002JD003185.

Lohmann, U., B. KÄrChER, J. HENDRICKS, 2004: Sensitivity studies of cirrus clouds formed by heterogeneous freezing in the ECHAM GCM. - J. Geophys. Res. 109, D16204, DOI:10.1029/2003JD004443.

McFarquhar, G.M., A.J. Heymsfield, 1998: The definition and significance of an effective radius for ice clouds. - J. Atmos. Sci. 55, 2039-2025.

MitCHELL, D.L., 2002: Effective diameter in radiative transfer: definition, applications and limitations. - J. Atmos. Sci. 59, 2330-2346.

RÄDEl, G., C.J. STUBEnRAuCH, R. Holz, D.L. MitChell, 2003: Retrieval of effective ice crystal size in the infrared: Sensitivity study and global measurements from the TIROS-N operational vertical sounder. - J. Geophys. Res. 108, 4281, DOI:10.1029/2002JD002801.

Roeckner, E., K. Arpe, L. BengtsSon, M. Christoph, M. Claussen, L. DüMenil, M. Esch, M. Giorgetta, U. Schlese, U. SchulzWEIDA, 1996: The atmospheric general circulation model ECHAM4: Model description and simulation of the present day climate. - Tech. Rep. 218, Max-Planck-Inst. für Meteorol., Hamburg, Germany.

Rossow, W.B., R.A. SCHIFFER, 1999: Advances in understanding clouds from ISCCP. - Bull. Amer. Meteor. Soc. 80, 2261-2287.

Scott, N.A., A. Chédin, R. Armante, J. Francis, C.J. Stubenrauch, J.-P. Chaboureau, F. Chevallier, C. Claud, F. Chéruy, 1999: Characteristics of the TOVS Pathfinder Path-B dataset. - Bull. Amer. Meteor. Soc. 80, 2679-2701.

SMith, W.L., H.M. WOOLF, M.C. HaYden, D.Q. Wark, L.M. MCMILLIN, 1979: The TIROS-N operational vertical sounder. - Bull. Am. Meteor. Soc. 60, 1177-1187.

Stephens, G.L., D.G. Vane, R.J. Boain, G.G. Mace, K. SASSEN, Z. WANG, A.J. ILlingWORTH, E.J. O'Connor, W.B. Rossow, S.L. Durden, S.D. Miller, R.T. Austin, A. Benedetti, C. Mitrescu, AND THE CloudSAT SCIENCE TEAM, 2002: The CloudSat mission and the A-Train: A new dimension of spacebased observations of clouds and precipitation. - Bull. 
Amer. Meteor. Soc. 83, 1771-1790.

Stubenrauch, C.J., A. Chédin, R. Armante, N.A. SCOTT, 1999a: Clouds as seen by infrared sounders (3i) and imagers (ISCCP). Part I: Evaluation of cloud parameters. - J. Climate 12, 2189-2213.

Stubenrauch, C.J., W.B. Rossow, N.A. Scott, A. CHÉDIN, 1999b: Clouds as seen by infrared sounders (3i) and imagers (ISCCP). Part III: Spatial heterogeneity and radiative effects. - J. Climate 12, 3419-3442.

Stubenrauch, C.J., F. EdDOUnia, G. Rädel, 2004: Correlations between microphysical properties of largescale semi-transparent cirrus and the state of the atmosphere. - Atmos. Res. 72, 403-423.

Stubenrauch, C.J., F. Eddounia, L. Sauvage, 2005: Cloud heights from TOVS Path-B: Evaluation using LITE observations and distributions of highest cloud layers. - J. Geophys. Res. 110, D19203, DOI:10.1029/2004JD005447.

Stubenrauch, C.J., A. Chédin, G. Rädel, N.A. SCOTT, S. SERRAR, 2006: Cloud properties and their seasonal and diurnal variability from TOVS Path-B. - J. Climate 19, 5531-5553.

Stubenrauch, C.J., F. Eddounia, J.M. Edwards, A. MACKE, 2007: Evaluation of cirrus parameterizations for radiative flux computations in climate models using TOVS - ScaRaB satellite observations. - J. Climate 20, 44594475.

Stubenrauch, C.J., S. Cros, N. Lamquin, R. ArMANTE, A. Ché́in, C. CREvoisier, N.A. SCOTt, 2008: Cloud properties from Atmospheric Infrared Sounder and evaluation with Cloud-Aerosol Lidar and Infrared Pathfinder Satellite Observations. - J. Geophys. Res. 113, D00A10, DOI:10.1029/2008JD009928.

Stubenrauch, C.J., S. Cros, A. Guignard, N LAMQUIN, 2010: A 6-year global cloud climatology from the Atmospheric InfraRed Sounder AIRS and a statistical analysis in synergy with CALIPSO and CloudSat. - Atmos. Chem. Phys., 10, 7197-7214.

Sundqvist, H., E. Berge, J.E. Kristiansson, 1989: Condensation and cloud parameterization studies with a mesoscale numerical weather prediction model. - Mon. Weather Rev. 117, 1641-1657.

WATERS, J.W., W.G. READ, L. FroideVAuX, R.F. JARNOT, R.E. COFIElD, D.A. FlOWER, G.K. LAU, H.M. PicketT, M.L. SANTEe, D.L. WU, M.A. BOYles, J.R. BURKE, R.R. LAY, M.S. LOO, N.J. Livesey, T.A. Lungu, G.L. Manney, L.L. NAKA-
MURA, V.S. PERUN, B.P. RidenOURE, Z. SHIPPONY, P.H. Siegel, R.P. Thurstans, 1999: The UARS and EOS Microwave Limb Sounder (MLS) experiments. - J. Atmos. Sci. 56, 194-218.

WebB, M., C. SENior, S. Bony, J.J. Morcrette, 2001: Combining ERBE and ISCCP data to assess clouds in the Hadley Centre, ECMWF and LMD atmospheric climate models. - Climate Dynam. 17, 905-922.

Williamson, D.L., P.J. RASCH, 1994: Water vapor transport in the NCAR CCM2. - Tellus 46A, 34-51.

Winker, D.M., C.R. TRePte, 1998: Laminar cirrus observed near the tropical tropopause by LITE. - Geophys. Res. Lett. 25, 3351-3354.

Winker, D.M., J. PELON, M.P. MCCORMICK, 2003: The CALIPSO mission: Spaceborne lidar for observation of aerosols and clouds. - Proc. SPIE Int. Soc. Opt. Eng., 4893, $1-11$.

Wu, D.L., J.H. JiAnG, C.P. DAVIS, 2006: EOS MLS cloud ice measurements and cloudy-sky radiative transfer model. - IEEE Trans. Geosci. Remote Sens. 44, 1156-1165.

Wu, D.L., R.T. Austin, M. DENG, S.L. Durden, A.J. HEYMSFIELD, J.H. JiANG, A. LAMBERT, J.-L. LI, N.J. Livesey, G.M. MCFARQUHAR, J.V. PitTMAN, G.L. Stephens, S. Tanelli, D.G. Vane, D.E. Waliser, 2009: Comparisons of global cloud ice from MLS, CloudSat, and correlative data sets. - J. Geophys. Res. 114, D00A24, DOI:10.1029/2008JD009946.

Wylie, D.P., W.P. MENZEL, 1989: Two years of cloud cover statistics using VAS. - J. Climate 2, 380-392.

Wylie, D.P., W.P. MEnZEL, 1999: Eight years of high cloud statistics using HIRS. - J. Climate 12, 170-184.

Wylie, D.P., W.P. Menzel, H.M. WoOlF, K.I. STRABALA, 1994: Four years of global cirrus cloud statistics using HIRS. - J. Climate 7, 1972-1986.

Yu, W., M. Doutriaux, G. SÈze, H. Le Treut, M. DESBOIS, 1996: A methodology study of the validation of clouds in GCMs using ISCCP satellite observations. Climate Dynam. 12, 389-401.

ZHANG, M.H., W.Y. LiN, S.A. KleIN, J.T. BACMEISTER, S. Bony, R.T. Cederwall, A.D. Del Genio, J.J. HACK, N.G. Loeb, U. LOHMANN, P. Minnis, I. Musat, R. Pincus, P. Stier, M.J. Suarez, M.J. WebB, J.B. Wu, S.C. XIE, M.-S. YaO, J.H. Zhang, 2005: Comparing clouds and their seasonal variations in 10 atmospheric general circulation models with satellite measurements. - J. Geophys. Res. 110, D15S02, DOI:10.1029/2004JD005021. 